\title{
CRIATIVIDADE NO INSTAGRAM COMO FERRAMENTA DE INOVAÇÃO PARA AS ORGANIZAÇÕES
}

\section{Creativity in Instagram as a tool for innovation to the organizations}

\section{Creatividad en Instagram como herramienta para la innovación de las}

organizaciones

\author{
Asdrúbal Borges Formiga Sobrinho ${ }^{1}$ \\ Alexandre Mota Barbosa ${ }^{2}$
}

\section{Resumo}

Criatividade tem sido importante por estar ligada à inovação. Foi observado o melhor aproveitamento de ideias das empresas para o desenvolvimento da inovação através de uma rede social com foco em imagens. Foi realizada pesquisa bibliográfica e análise empírica do Instagram, envolvendo coleta de dados nos perfis das empresas. Como resultados, duas organizações mostraram a importância e os benefícios de seus diferenciais na rede social.

Palavras-chave: criatividade, inovação, imagens, comunicação organizacional, Instagram.

\begin{abstract}
Creativity has been important cause it is linked to innovation. It was observed the best use of ideas of businesses to develop innovation through a social network focused on images. It was made literature research and empirical analysis of social network Instagram, involving collecting data on the profiles of the companies. As results, two organizations showed the importance and benefits of their differential on the social network.
\end{abstract}

Keywords: creativity, innovation, images, organizational communication, Instagram.

\footnotetext{
${ }^{1}$ Doutor em Psicologia pela UnB, mestre em Comunicação Social pela UnB e bacharel em Publicidade e Propaganda pela UnB. Professor adjunto da Faculdade de Comunicação e do Programa de Pós-graduação em Comunicação da UnB. Pesquisa sobre comunicação, criatividade, cultura, consumo e cidadania. Email: asdru_bal@uol.com.br.

${ }^{2}$ Graduando em Comunicação Organizacional pela Universidade de Brasília. E-mail: alexandre_099@hotmail.com
} 


\section{Resumen}

La creatividad ha sido importante para ser vinculado a la innovación. Fue observado el mejor uso de las ideas de las empresas a desarrollar la innovación a través de una red social enfocada en imágenes. Se llevó a cabo la literatura y un análisis empírico del Instagram, buscando se datos sobre en los perfiles de las empresas. Como resultado, las dos organizaciones han mostrado la importancia y los beneficios de suyos diferenciales en la red social.

Palabras-clave: creatividad, innovación, imágenes, comunicación organizacional, Instagram.

\section{INTRODUÇÃO}

O Instagram é uma rede social gratuita para compartilhamento de fotos e vídeos, onde é possível aplicar filtro nas imagens e depois publicá-las, possibilitando que outros usuários possam visualizar, curtir e comentar, além de compartilhar em outras redes sociais como Twitter e Facebook. Foi desenvolvido para a publicação de fotos com aparência profissional resultante dos efeitos dos filtros.

Criado pelo engenheiro de programação Kevin Systrom e pelo brasileiro Mike Krieger, foi lançado para o público no dia 6 de outubro de 2010. Inicialmente, o aplicativo era disponível apenas para usuários de aparelhos da Apple e alcançou 1 milhão de usuários, em dezembro do mesmo ano. Em agosto de 2011, o aplicativo chegou à marca de 150 milhões de fotos postadas e, no mês seguinte, já eram mais de 10 milhões de usuários cadastrados, de acordo com o site oficial do Instagram.

O aplicativo deixou de ser exclusivo para aparelhos da Apple e ganhou a versão para Android, em 12 de abril de 2012, para ampliar o público consumidor. Em menos de 24 horas, foram feitos 1 milhão de downloads na nova plataforma. No mesmo mês, foi comprado pelo Facebook e, em Julho de 2012, já era utilizado por 80 milhões de usuários. Assim o Instagram se tornou um dos aplicativos para dispositivos móveis mais popularizados do mundo.

Em novembro de 2012, o Instagram lançou uma página na web, permitindo aos usuários uma nova possibilidade de visualizar, curtir e comentar as fotos, não sendo possível postar. Outro grande momento para a empresa foi em fevereiro de 2013, quando anunciou a marca de 100 milhões de usuários ativos mensalmente na rede. 
O CEO do Instagram, Kevin Systrom, anunciou, em Junho de 2013, uma novidade no aplicativo, a chegada da ferramenta de vídeos na rede social. O recurso permite a gravação de um vídeo de até 15 segundos. Além disso, Systrom comunicou que a rede superou a marca de 130 milhões de usuários, que já compartilharam 16 bilhões de fotos no total.

Os números não pararam de aumentar. Em março de 2014, o Instagram revelou que chegou a 150 milhões de usuários, atingindo o patamar de 55 milhões de fotos compartilhadas diariamente. Ao todo, há 1,2 bilhões de likes em média, por dia. $\mathrm{O}$ fator essencial para esse sucesso é a facilidade de uso do aplicativo, que conta com uma interface simples e prática, possibilitando uma velocidade maior para visualizações e publicações.

Em Psicologia da Criatividade, Lubart (2007) comenta que a criatividade se encontra entre a novidade e a adaptação, considerando, por exemplo, que uma produção criativa adaptada pode satisfazer as diferentes dificuldades dos usuários. Para Lubart, que trata de questões motivadoras para o processo criativo:

a criatividade é a capacidade de realizar uma produção que seja ao mesmo tempo nova $e$ adaptada ao contexto no qual ela se manifesta [...]. Essa produção pode ser, por exemplo, uma ideia, uma composição musical, uma história ou ainda uma mensagem publicitária (LUB ART, 2007: 16).

Porém, o autor também considera que:

Além dos aspectos da novidade e da adaptação, há outras características que influenciam frequentemente os juízos a propósito da criatividade, como a qualidade técnica de um]

a obra, ou ainda a importância da produção a respeito das necessidades da sociedade. Assim, um trabalho tecnicamente bem feito pode melhor destacar a novidade e o valor de uma idéia do que o mesmo trabalho apresentado de maneira mais relapsa (LUBART, 2007: 17)

$\mathrm{O}$ autor considera importante para a criatividade que a pessoa pense de forma diferente, adotando novas alternativas de pensamentos com base nas diferentes motivações, ou seja, a criatividade está relacionada aos processos de pensamento, à imaginação e à originalidade. Inicialmente com base nestas considerações, este estudo mostra que a nova ferramenta digital é bastante indicada para promoção de uma marca ou de um produto, devido às diversas opções de interação entre os públicos. Além da praticidade operacional, tem um grande alcance comunicacional, considerando a 
internet um novo meio de comunicação de massa em que é possível atingir um grande número de usuários.

Para fundamentar a abordagem do referido contexto, o presente artigo apresenta conceitos de interatividade, criatividade e inovação; e trata da importância deles na utilização das redes sociais, por parte das organizações. Um dos objetivos é investigar a importância da utilização das novas mídias, mais especificamente o Instagram, de forma criativa, e mostrar como as empresas se destacam, levando em consideração essa nova realidade, em que organizações de diversas naturezas entram nas redes sociais para estabelecer um relacionamento mais próximo com seus públicos.

\section{INTERATIVIDADE}

Os teóricos da Comunicação costumavam definir como mídia de massa apenas a imprensa, a televisão, o cinema e o rádio. No início da década de 1990, os sistemas eletrônicos interativos, baseados em computação e telefonia, eram definidos como mídias emergentes (DEFLEUR \& BALL-ROKEACH, 1993), mas, atualmente, a internet já é tratada como uma nova mídia de massa (HOHLFELDT, MARTINO \& FRANÇA, 2001; MORAES, 2003), ou seja, uma mídia de fácil acesso, impessoal e de ampla difusão geográfica.

A rede de computadores que forma a internet saiu das redes de pesquisas de universidades e outras instituições para se tornar um sistema de comunicação que abrange expressivas parcelas da população, em grande parte do mundo, o que a transformou em parte da cultura de massa (CASTELLS, 2000). A internet é a mídia com características de interatividade radicalmente diferentes dos demais meios de comunicação (CASTELLS, 2003; NICOLACI-DA-COSTA, 2002 E 2003; TERÊNCIO \& SOARES, 2003).

A comunicação de massa tradicional pressupõe uma difusão de um para muitos, unidirecional dos meios de comunicação para a sociedade, enquanto a convergência dos meios digitais através da internet permite também a comunicação de um para um, muitos para um ou muitos para muitos, através de e-mail, grupos de discussão em websites e sistemas de chat (LEVY, 2003; CASTELLS, 2003). Para Castells (2003) o aspecto inédito é que, pela primeira vez na História, existe uma capacidade maciça de comunicação não intermediada pelas empresas e meios de comunicação de massa. Isso derruba, em parte, a suposta vitimização de indivíduos frente aos meios de 
comunicação.

No contexto contemporâneo, no qual as tecnologias estão cada vez mais inseridas na vida das pessoas, é difícil nos imaginar sem o telefone móvel - há um tempo utilizado não somente para o fim da conversação - e - sem conexão com a internet. Segundo Lemos (2013), o uso das novas tecnologias pela sociedade contemporânea amplia o potencial comunicativo, proporcionando uma troca de informações sob as mais diversas formas. O telefone celular tornou-se um dispositivo de múltiplas convergências midiáticas (LEMOS, 2007), ou seja, os novos aparelhos celulares agregam diversas opções aos usuários, como câmera fotográfica, agenda, acervo de músicas e vídeos, além das possibilidades de interação geradas pelo acesso à internet, como e-mails, downloads, bate-papo e a própria ferramenta de publicação de fotos através de programas instalados no dispositivo. Nesse sentido, podemos observar como hoje a presença de uma ferramenta tecnológica é importante nesses novos processos de troca de informação. Conforme explica o pesquisador brasileiro André Barbosa Filho:

A interatividade pode ocorrer face a face ou mediada por uma plataforma tecnológica. A partir do uso da mediação tecnológica nos anos 1990, a interatividade tornou-se novo campo de investigação. Isso porque as sucessivas inovações tecnológicas estão sempre apresentando novidades como intermediárias ou facilitadoras da comunicação humana, superando antigas barreiras, como o tempo e o espaço. (BARBOSA FILHO, 2010: 707).

A definição de Pierre Lévy (1999: 17) para ciberespaço como um novo espaço de comunicação e sociabilidade em que se cria uma nova possibilidade de contato social, extrapolando os limites naturais de espaço e de tempo com os quais até então estávamos acostumados, aplica-se a estas redes sociais e à comunicação mediada por um computador, considerando os dispositivos móveis espécies de computador. Algumas pessoas que usualmente se organizavam em espaços físicos ou se vinculavam por uma relação de proximidade, agora, com a internet, podem se agrupar por afinidades, valores afetivos e interesses em comum, e grande parte do seu espaço passa a ser o próprio ambiente virtual ou on-line.

Nos Estados Unidos, por exemplo, a internet teve papel fundamental na eleição do presidente Barack Obama, com a utilização da rede social Twitter, conforme menciona Jenkins (2009). Não foi diferente em 2012, quando a equipe de Obama seguiu 
com a mesma estratégia e entrou no Instagram para mobilizar os internautas. O próprio Instagram deu as boas vindas ao presidente:

Estamos felizes de dar as boas vindas ao presidente Barack Obama ao Instagram! Estamos ansiosos para ver como o presidente Obama usará o Instagram para dar aos seguidores um aspecto visual do que acontece no dia-a-dia de um presidente dos Estados Unidos. (SYSTROM KEVIN, 2012)

O exemplo indica que os meios de comunicação podem ter a função de construir um sentido estratégico para as decisões e ações de uma organização e contribuir para a busca de crescimento da organização no cenário social. O alinhamento entre os objetivos da organização e da comunicação é essencial para o alcance dos resultados esperados. A organização que estiver mais preparada para gerar soluções e definir estratégias práticas, originais e úteis para o enfrentamento dos desafios do mercado e da concorrência, estará mais apta a sobreviver e atingir objetivos num mundo em constantes mudanças.

\section{CRIATIVIDADE E INOVAÇÃO}

$\mathrm{Na} w e b$, parece existir um padrão a ser seguido, pois em grande parte dos portais e sites os formatos são pré-determinados. Entretanto, o trabalho criativo, muitas vezes, consegue ultrapassar esses limites e cria novas formas de participação. A constante modernização das ferramentas tecnológicas proporciona maior participação dos usuários no uso de sites e de outras mídias. O poder de participação, interação e mobilização também se ampliou potencialmente. Os novos meios de comunicação conseguem ultrapassar as barreiras da televisão e chegar com mais destaque à Internet, já que o internauta tem expectativa de interatividade, mesmo que de forma inconsciente, e poderá ser atingido diretamente, de maneira possível somente no ambiente da Internet.

A popularidade das redes sociais mudou o relacionamento das empresas com os clientes. Por se tratar de novas tecnologias, as empresas, além de interativas, devem buscar ser criativas no Instagram, pois de forma planejada, podem se tornar uma nova maneira de se relacionar com a sociedade como um todo e, de forma especial, com os diferentes públicos de interesse. Atrelada a todos esses aspectos, ainda que de forma discreta, mas crescente, a criatividade - empregada na geração de grandes ideias contribui para que as empresas mostrem sua busca por um diferencial. 
A criatividade é inerente ao ser humano, que tem uma necessidade de solucionar problemas. Para que a criatividade contribua na produção de inovações é importante que haja não somente um rearranjo de ideias e conceitos já existentes, mas também se torna necessário que o resultado final forme um novo produto, um novo método, uma resolução de problema que obtenha resultados de valor para um indivíduo, uma sociedade ou uma organização.

A originalidade é outro fator que indica o nível de criatividade presente como elemento central, em quase todas as definições. Guilford (1989), citado por Lubart (2007), chegou a afirmar que a originalidade é o centro e a síntese da criatividade. Originalidade pode ser entendida como algo originário ou ponto de partida, como resposta fora do comum, como criações raras ou remotas ou como respostas engenhosas ou de talento. Nesse último caso, seja em nível individual ou organizacional, a resposta oferecida deve se caracterizar pela presença de uma novidade, mas de maneira construtiva, deixando de lado, quando necessário, os padrões estabelecidos (TORRE, 2006).

Para Bruno Faria, a partir da análise da produção científica sobre criatividade no contexto das organizações,

a criatividade é a geração de idéias, processos, produtos ou serviços novos que possam produzir alguma contribuição valiosa para a organização elou para o bem estar das pessoas que trabalham naquele contexto e que possuam elementos essenciais à sua implementação. (BRUNO-FARIA, 2013:117).

Este conceito nos traz a possibilidade de trabalhar com inovação, que podemos considerar a implementação dessas novas idéias, produtos ou serviços, ou seja, colocar a criatividade em prática. Porém, criatividade e inovação não são a mesma coisa, pois embora toda produção criativa seja inovadora, nem toda produção inovadora é criativa. No Instagram, por ser uma rede com um apelo visual bem forte, as imagens tendem a ganhar prioridade diante da descrição verbal de um produto.

Há poucas dúvidas de que o estilo de vida contemporâneo tenha sido crucialmente influenciado pelas transformações que nele foram instauradas pelo advento da fotografia. Em textos impressos, a palavra é o elemento fundamental, enquanto os fatores visuais como o cenário físico, o formato e a ilustração são secundários ou necessários apenas como apoio. Nos modernos meios de comunicação acontece exatamente ao contrário. O visual predomina, o verbal tem a função de acréscimo. (DONDIS, 1993:12) 
Logo, utilizar uma plataforma midiática que tem como principal objetivo o compartilhamento e, principalmente, o tratamento da imagem pode ser uma escolha inovadora, pois se diferencia das mídias tradicionais. Porém, é importante levar em consideração a qualidade técnica da imagem. Muitas empresas não se preocupam com a qualidade das fotografias utilizadas em suas mídias, quando se observa, por exemplo, ângulo e enquadramento.

É necessário ter em mente que a utilização de redes sociais requer a mesma preocupação com produção, especialmente quando estamos lidando com imagem. Uma produção mal feita pode ter um efeito negativo no resultado final de uma ideia e, consequentemente, no resultado da imagem da empresa, de maneira geral. Dessa forma, é ponto chave entender que a Comunicação Organizacional, área da comunicação responsável por cuidar da imagem corporativa, faz-se indispensável para que a organização alcance um lugar de destaque no mercado e ganhe notoriedade perante seus públicos (KUNSCH, 2003).

A adesão ao uso de ferramentas de mídias sociais, por parte das organizações, deixou de ser uma opção para empresas que desejam permanecer competitivas. Esses novos canais de relacionamento são o novo espaço em que os comunicadores devem observar e serem observados. Consequentemente, o Instagram tem se tornado eficaz em ações de comunicação com seus públicos. A importância de ações desse tipo é apontada por Scroferneker, pois, conforme a autora, a comunicação organizacional "abrange todas as formas de comunicação utilizadas pela organização para relacionar-se e interagir com seus públicos" (2000: 01). Esta interação exige cada vez mais criatividade das empresas e pode ser bastante útil na consolidação do conceito de uma marca.

\section{POR QUE A LOJA FARM E O BISTRÔ PARIS 6 SE DESTACAM?}

Foi feita uma pesquisa exploratória sobre a comunicação realizada por empresas de roupa e restaurantes, analisando-se, de forma quantitativa e qualitativa, a forma como marcas se relacionam no Instagram. Foram analisados 3 restaurantes de mesmo porte, o Coco Bambu, Sushi Leblon e o Paris 6. Todos eles contam com uma ampla rede de clientes, diariamente, mas no Instagram foi observado que o Paris 6 se destacava pelo número de seguidores e pelo volume de compartilhamento de informação. A outra parte da pesquisa foi sobre lojas de roupas. Foram analisados os perfis de Maria Filó, Farm e Osklen. As três lojas são bem ativas no Instagram, mas foi observado um diferencial no 
perfil da Farm. Nesse âmbito, o presente estudo tem o propósito de analisar como é feito o uso do Instagram pela Farm, empresa de moda Feminina, e pelo Restaurante Bistrô Paris 6, duas organizações que, com base em originalidade na estratégia de comunicação, estão se destacando na rede social, atingindo grande visibilidade e atraindo muitos seguidores.

Após as escolhas dos perfis, foram analisadas as duas empresas, durante dois períodos. O primeiro foi do dia 16 ao dia 23 de abril de 2014. E o segundo, do dia 29 de abril ao dia 6 de maio do mesmo ano. Ambas as semanas contavam com feriado, o que deu a possibilidade de observar o movimento no perfil das empresas em dias comerciais, fins de semana e feriados. Essas empresas que utilizam o Instagram como um meio para promover a marca podem ir além do tradicional. Isto significa que a postagem de conteúdo não deve ser feita apenas durante o horário comercial, mas também durante a noite e nos finais de semana, principalmente porque o principal meio de visualizar o Instagram é através de um dispositivo móvel, que as pessoas podem usar em qualquer lugar e em qualquer horário.

\subsection{Instagram oficialda Farm @adorofarm}

No primeiro período, foram publicadas 34 fotos e 1 vídeo. A foto com menos curtidas, 3.078, foi postada no dia 23 de abril, às $13 \mathrm{~h}$. O conteúdo da foto era de informação sobre o estoque de produtos da loja. Grande parte dos 124 comentários era sobre preços, disponibilidade dos produtos e lojas nas quais ainda podiam ser encontrados. Alguns seguidores tiveram seus comentários respondidos. A seguidora @jussaralage perguntou: “vai ter reposição das jaquetas?”. O perfil da loja respondeu: "Se rolar outra reposição, a gente avisa". Podemos observar a interatividade neste caso e a preocupação da loja em manter os clientes informados.

Já a foto com mais likes, 11.063, foi publicada no dia 21 de abril, às 16h50. A foto é de uma seguidora que usou a hashtag \#tonoadorofarm e teve sua imagem escolhida para o perfil oficial. A fotografia mostra uma mulher fazendo sup na Barra de Guaratiba, no Rio de Janeiro, e causa boa impressão entre os seguidores, como indicam os comentários, que chegaram a 145. @pilatesmaryanafonte comentou: "Lindo demais!!”. Já @julia_kacurin marcou um amigo na foto e disse “olha q foto maneira". O uso de hashtags no Instagram, assim como em outras redes sociais, auxilia na segmentação do conteúdo e facilita as buscas dos usuários. Nesse caso, podemos dizer 
que há uma motivação extrínseca por parte das pessoas que utilizam essa hashtag, que deseja ter sua foto publicada no perfil oficial da marca e consequente reconhecimento público entre os seguidores da mesma como recompensa.

No segundo período, foram postadas 45 fotos e a foto com menos curtidas, 1.513, divulgava uma nova rede social em que a marca foi inserida. Postada no dia 29 de abril, teve apenas 8 comentários. Já a fotografia que os seguidores mais curtiram nesse período foi a de um filhote de cachorro. A foto teve 10.811 likes e foi postada no dia 5 de maio. A seguidora postou no seu perfil usando a hashtag \#tonoadorofarm e teve sua imagem publicada no perfil da empresa. Um dos 189 comentários foi da seguidora @isaguero_, que achou "a coisa mais fofa", assim como muitas outras pessoas.

Usando a hashtag \#tonoadorofarm, a marca convida consumidores e seguidores a marcar fotos que mostrem o Rio e o estilo de vida da Zona Sul carioca, divulgando as imagens selecionadas no perfil oficial. Até o dia 14 de maio de 2014, segundo o Instagram, 121.440 fotos têm essa marcação. As fotografias selecionadas são imagens que motivam a criatividade e o desejo de compartilhar esse estilo de vida. As imagens, apesar de não seguirem uma padronização, têm muita cor e uma grande valorização do contato com a natureza. A criatividade, neste caso, segundo Bruno-Faria, como supracitado, pode ser vista como a produção, por parte dos consumidores, de ideias novas e geradoras de valor para a organização. "Identificamos que aquele não era um canal comercial, mas sim um canal de contemplação, de escape", explica no site da empresa, André Carvalhal, diretor de marketing da Farm, ao falar sobre a empresa no Instagram. E, além disso, a marca, que tem seus produtos exclusivamente femininos, passa a ser reconhecida pelo público masculino na rede social por ir além dos produtos e sobretudo por possibilitar às pessoas ver o Rio de Janeiro sob outro olhar, não somente considerando os pontos turísticos, como usualmente é mostrado nas grandes mídias.

Esse é o grande diferencial da marca no Instagram: a clareza do objetivo da marca mostrada através das fotos produzidas por seu público, fazendo com que o Instagram deixe de ser utilizado apenas como vitrine para mostrar os produtos e passe a exibir um elemento importante da identidade da marca, que é um dos estilos de vida da zona sul carioca.

\subsection{Instagram oficialdo Paris 6 @paris_6}


Outra empresa com destaque no Instagram é o Bistrô Paris 6, um restaurante Fracês 24h, localizado no Rio de Janeiro e em São Paulo. O proprietário, Izaac Azar, é amigo de celebridades e batiza os pratos com seus nomes. A justificativa para o su cesso vem do marketing por meio de fotos com celebridades que frequentam o restaurante, sendo este o diferencial da marca, que já ultrapassa 173 mil seguidores.

Durante o primeiro período, foram postadas 18 fotos no perfil @paris_6. A foto com menos curtidas, 1.145, divulgava uma exposição de quadros que ocorreria na galeria do restaurante. E a foto com mais likes, neste período, postada às $18 \mathrm{~h} 20$ do dia 27 de abril, mostrava um prato digno de revista de culinária, batizado de Grand Gateau Chocolat a Paloma Bernardi. Os 451 comentários na foto traduziam o que a imagem mostrava, muitos elogios e vontade de experimentar. A seguidora @dmigarashi marcou um amigo e disse "o nosso próximo encontro tem que ser no paris 6 pra comer o grandgateau".

No segundo período, foram postadas 10 fotos. A imagem com menos curtidas, 1.516, postada no dia 30 de abril, mostrava os bastidores de uma homenagem ao dono do restaurante, em uma premiação. E a fotografia mais curtida neste período, postada no dia 3 de maio, mostra um prato de sobremesa aparentemente saboroso, homenageando a atriz brasileira Giovanna Lancelotti, que em seu perfil, com mais de 700 mil seguidores, também postou uma foto com o prato levando a marca do restaurante. No Instagram do Bistrô essa foto chegou a sete mil e quinhentas curtidas, um possível reflexo do compartilhamento da informação no perfil da atriz.

Há uma grande interação entre o público e o restaurante, por meio dos comentários das fotos dos pratos e dos artistas. As pessoas marcam amigos e isso faz com que a outra pessoa conheça o perfil e passe a conhecer o nome do restaurante. A criatividade expressa nos pratos, por terem nomes de pessoas famosas, também ajuda a despertar curiosidade dos clientes, sendo um grande atrativo para seguir o perfil e conhecer o restaurante. Muitos desejam tirar fotos no restaurante e marcar o nome do prato que comeu, compartilhando e fazendo aumentar o público na rede social.

\section{CONSIDERAÇÕES FINAIS}

Neste artigo, buscamos abordar o uso da rede social Instagram pelas organizações, de forma criativa. A simplicidade e a proximidade com os usuários do aplicativo fazem com que o Instagram represente um importante canal de comunicação 
para grandes e pequenas organizações. As empresas perceberam a importância de buscar, nas redes sociais, novos potenciais e diferenciais competitivos. O principal resultado foi perceber que adotar inovações nas redes sociais representa gerar, desenvolver e implantar ideias ou procedimentos novos para consolidação de uma marca.

As empresas destacadas mostraram que, com as novas tecnologias, os usuários têm um grande poder participativo e, assim, podem ajudar na melhoria dos produtos e serviços prestados, além de contribuírem para a redução de custos, por se tratar de um meio gratuito. A revolução na comunicação provocada pela Internet fez com que as empresas tivessem que repensar sua comunicação com os consumidores. Também representou novas oportunidades de gerar interação. Observaram o cenário de crescimento do aplicativo e souberam aproveitar o diferencial para crescer em número de seguidores e ter um grande número de compartilhamento de informações através de uma estratégia criativa.

\section{REFERÊNCIAS BIBLIOGRÁFICAS}

BARBOSA FILHO, Andre. Comunicação digital: educação, tecnologia e novos comportamentos. $1^{\text {a }}$ edição. São Paulo: Paulinas, 2008

CASTELLS, M. Internet e Sociedade em Rede. In Moraes, D. (org.), Por uma

Outra Comunicação: Mídia, Mundialização Cultural e Poder. Rio de Janeiro:

Record, 2003.

DEFLEUR, M. L., BALL-ROKEACH, S. Teorias da Comunicação de Massa. Rio de Janeiro: Jorge Zahar, 1993

DONDIS, Donis A. Sintaxe da linguagem visual. São Paulo: Martins Fontes, 1993.

FERREIRA, Baronso. INSTAGRAM E PUBLICIDADE: Manual de uso prático do Instagram para empresas. 2013 Disponível em < http://pt.slideshare.net/baronsolucena/trabalho-final-formatado-para-impresso> Acesso em: 27/10/2014

G1. Campanha de Obama cria perfil no Instagram. 2012 Disponível em <http://g1.globo.com/mundo/noticia/2012/01/campanha-de-obama-cria-perfilno-instagram.html> Acesso em: 27/10/2014

HOHLFELDT, A., MARTINO, L. C., FRANÇA, V. V. (orgs.) Teorias da

Comunicação: Conceitos, Escolas e Tendências. Petrópolis, Rio de Janeiro: Vozes, 2001 
JENKINS, Henry. Cultura da convergência. São Paulo: Aleph, 2009.

KUNSCH, Margarida M. K. Planejamento de relações públicas na comunicação integrada. São Paulo: Summus, 2003.

LEMOS,Andre. Olhares sobre a cibercultura, Porto Alegre, Sulina, 2003.

LÉVY, Pierre. Cibercultura. São Paulo: Edições 34, 1999.

LUBART, Tody. Psicologia da Criatividade. $1^{\mathrm{a}}$ edição. Porto Alegre: Artmed, 2007.

MARTINO, L. C. Interdisciplinaridade e Objeto de Estudo da Comunicação. In Hohlfeldt, A., Martino, L. C., França, V. V. (orgs.). Teorias da Comunicação:

Conceitos, Escolas e Tendências. Petrópolis, Rio de Janeiro: Vozes, 2001.

SCROFERNEKER, Cleusa Maria Andrade. Perspectivas teóricas da comunicação organizacional. Manaus: Anais, 2000.

Artigo submetido: 03/05/2014

Artigo aprovado: 03/06/2014 